\title{
Amelioration of 5-FU induced toxicity by using RF under white light: An in vitro study
}

\author{
Eram Husain, Sandesh Chibber and Imrana Naseem* \\ Department of Biochemistry, Faculty of Life Sciences, Aligarh Muslim University, Aligarh, India
}

\begin{abstract}
5-Fluorouracil (5-FU) is a potent photosensitizer used in colon and rectal cancer. A major drawback associated with 5-FU chemotherapy is its toxicity towards normal tissues by generation of reactive oxygen species (ROS). Riboflavin (RF) is a well known photosensitizer and has no adverse effect. Previously, we have reported the ameliorative effect of photoilluminated RF in case of cisplatin induced toxicity both in vitro and in vivo. Accordingly, we have extended our work and have tried to demonstrate with the help of carbonyl assay that the rise in the carbonyl groups reached a certain level at particular concentration of 5-FU and after which no increase in oxidative damage of protein was observed. However, on addition of RF in the reaction the photo excitation of 5-FU was inhibited at lower concentration. Moreover, plasmid nicking also elucidate that the nicking activity is minimally affected by the incorporation of 5-FU at higher concentration in the reaction and on addition of RF at lower concentration of 5-FU the nicking of plasmid was masked. Furthermore, on incubation of lymphocytes with lower concentration of 5-FU in presence of RF as compared to 5-FU alone led to a significant decrease in tail length of DNA when measured by comet assay. Thus, study show that 5-FU behaves in a biphasic manner, at lower concentrations of the drug in which RF inhibits the photoactivation leading to quenching in the ROS generation while at higher concentration the drug dimerization is thought to be the plausible reason for the observed results. In conclusion, our results suggest that 5 -FU induced toxicity may be blunted by using RF under white light.
\end{abstract}

\section{Introduction}

5-Fluorouracil (5-FU) is a potent photosensitizer which is used in the treatment of colon and rectal cancers. 5-FU acts in a similar manner as 5-bromouracil, its main biochemical action is as antimetabolite of the uracil in anabolic pathways [1]. The cytotoxic effect of 5-FU in most systems is attributed primarily to its conversion into 5-fluoro-2'deoxyuridine monophosphate (FdUMP) which is a potent inhibitor of thymidylate synthase a pivotal enzyme in pyrimidine biosynthesis [2] Thymidylate synthase is a vital enzyme for the growth of tumors also. 5-FU show greater selectivity against solid tumors which are showing multiresistance to drugs than do other antitumor agents [3].

Vitamin B2 or riboflavin (RF), chemically known as 6,7-dimethyl9-D-1- ribityl-isoalloxazine, is an essential water soluble vitamin. RF application in the field of photobiology has been developed into an effective mode of treatment for various diseases like neonatal hyperbilirubinemia, pigmented skin lesions and blue nevus [4,5]. Further, its application in inactivation of neurotoxin A, neutralization of carcinogens, killing of tumors and sterilization of platelets concentrates increased its horizons of clinical usage under photodynamic therapy (PDT) [6,7].

According to a reported study by Yasumoto et al. [8] bioreductive prodrugs such as tegafur can be activated into their radical intermediates under aerobic conditions. However, under hypoxic conditions (e.g., in solid tumors), this oxidation is much slower and usually increases the levels of toxic radical intermediates, resulting in a solid tumor-selective therapy. Hydrated electrons can initiate reductive activation of the prodrugs under hypoxic conditions. It was reported that galvanostatic electrolysis or radiation-induced oxidation of aqueous 5-FU solution yield the $\mathrm{N}_{1}-\mathrm{C}_{5}$-linked dimer hydrate of 5-FU via head-to-tail coupling between the $\mathrm{N}_{1}$-centered radical and $\mathrm{C}_{5}$-centered radical of 5-FU [9].
Chemotherapy agents have a low therapeutic index thus also affecting normal cells beside cancer counterparts and often induce side effects in cancer patients that severely limit their activity. The increased in the intracellular ROS caused by 5 -FU may lead to lipid peroxidation of cardiac membranes [2]. Moreover, the potential adverse effects of occupational exposure to antineoplastic agent like $5 \mathrm{FU}$ may also lead to genotoxicity [10]. Thus, quantification and monitoring of antineoplastic agent like 5-FU that indicates occupational exposure is very important to prelude genotoxicity. 5-FU induces apoptosis in rat cardiocytes through intracellular oxidative stress [11]. It was also reported that low doses of 5-FU also exhibited abnormal changes, including periportal fibrosis, degeneration of hepatic cords and increased apoptosis [12]. Furthermore, clinically relevant concentrations of 5-FU were also found to be toxic for both central nervous system (CNS) progenitor cells and non-dividing oligodendrocytes in vitro and in vivo [13]. In context to genotoxicity, 5-FU was observed to induce MN-RET in a dose-dependent manner; experiments were performed with 5-FUtreated SD rats using a 3-day study design [14]. The aforementioned are some of the undesired toxic effects of 5-FU despite 5-FU proven therapeutic efficacy.

The present study was designed to increase the therapeutic window of RF by blunting the toxic effects of 5-FU in case of combination. It is

Correspondence to: Prof. Imrana Naseem, Department of Biochemistry, Faculty of Life Sciences, Aligarh Muslim University, Aligarh, U.P., India, Tel: 91-5712700741; Fax: 91-571-2706002; E-mail: imrananaseem2009@gmail.com

Key words: Riboflavin, 5fluorouracil, photosensitizer, dimerization, Chemophototherapy

Received: November 24, 2014; Accepted: February 22, 2015; Published: February 27, 2015 
a preliminary attempt to suggest an alternative regimen for the cancer patients undergoing 5-FU based chemotherapy which is in accordance with our previous reported in-vitro and in vivo cisplatin studies [15-17].

\section{Chemicals and reagents}

5-FU, RF, agarose, low melting point agarose, Roswell Park Memorial Institute (RPMI) 1640 medium, Triton X-100, trypan blue and histopaque 1077 were purchased from sigma chemical co. (St. Louis, MO, USA.). Plasmid pUC18 was purchased from genei, Banglore, India. All other chemicals used were of analytical grade. Phosphate-buffered saline (PBS, $\mathrm{Ca}^{2+}$ and $\mathrm{Mg}^{2+}$ free) was used to prepare all the reaction mixtures.

\section{Irradiation procedure}

Each sample was placed in front of a white fluorescent tube at a distance of $10 \mathrm{~cm}$ [18]. At this point fluency rate was $38.6 \mathrm{~W} / \mathrm{m}^{2}$ as measured by power meter (model: lasermate coherent, USA), there was no measurable change in temperature of the solution at the end of irradiation.

\section{Measurement of hydroxyl radical}

The generation of hydroxyl radical was measured by the method of Gutteridge, (1992) [19]. Calf thymus DNA $(100 \mu \mathrm{g})$ was used as a substrate and malondialdehyde generated from deoxyribose radicals was assayed by recording the absorbance at $532 \mathrm{~nm}$.

\section{Carbonyl estimation}

The amount of carbonyl groups formed was determined by the method of Nakagawa et al. [20]. $2 \mathrm{ml}$ of reaction mixture was taken in a glass tube, and blended with $0.5 \mathrm{ml}$ of $10 \mathrm{mM}$ 2,4-dinitrophenylhydrazine in $2.5 \mathrm{M} \mathrm{HCl}$. The mixture was left for $1 \mathrm{~h}$ at room temperature then $0.5 \mathrm{ml}$ of $20 \%$ trichloroacetic acid solution was added to the tube and was then left in an ice bucket maintained at $4^{\circ} \mathrm{C}$ for $10 \mathrm{~min}$ followed by centrifugation at $12,000 \mathrm{rpm}$ for $15 \mathrm{~min}$. Supernatant was discarded, the protein pellets were washed three times with $3 \mathrm{ml}$ ethanol: ethyl acetate $(1: 1, \mathrm{v} / \mathrm{v})$ and dissolved in $2 \mathrm{ml}$ of $6 \mathrm{M}$ guanidine ( $\mathrm{pH} 2.3$ ) with vortex mixing, then absorbance was calculated using a molar absorption coefficient of $22,000 \mathrm{M}^{-1} \mathrm{~cm}^{-1}$.

\section{Measurement of $\boldsymbol{\alpha}$-helical contents of protein}

Circular Dichroism measurement was carried out with a Jasco spectropolarimeter, model j-720 using K2D3 software. The instrument was calibrated with D-10-camphorsulfonic acid. All the CD measurements were made at $25^{\circ} \mathrm{C}$. Helical content was calculated from the Mean Residue Ellipticity (MRE) values at $222 \mathrm{~nm}$ using following equation as described by Chen et al. [16,21].

$$
\% \text { a-helix }=\left(\mathrm{MRE}_{222 \mathrm{~nm}}-2340 / 30300\right) \times 100
$$

\section{Treatment of plasmid pUC18 DNA with photoillumi- nated 5-FU in presence and absence of RF}

Reaction mixture $(40 \mu \mathrm{l})$ contained $10 \mathrm{mM}$ tris- $\mathrm{HCl}(\mathrm{pH} 7.5), 0.5$ $\mu \mathrm{g}$ plasmid pUC19 DNA, 5-FU $(10-50 \mu \mathrm{M})$ and RF at concentration of $50 \mu \mathrm{M}$. Incubation was performed under white light for $1 \mathrm{~h}$. After incubation, $10 \mu \mathrm{l}$ of a solution containing $40 \mathrm{mM}$ EDTA, $0.05 \%$ bromophenol blue tracking dye and $50 \%$ (v/v) glycerol was added and the solution was subjected to electrophoresis in submarine $1 \%$ agarose gels. Ethidium bromide stained gel was then viewed and photographed on a UV-transilluminator.

\section{Isolation of lymphocytes}

Heparinized blood samples $(2 \mathrm{ml})$ from a single healthy human donor (females, 25 year with no smoking habit) was obtained by venupuncture and diluted suitably in $\mathrm{Ca}^{2+}$ and $\mathrm{Mg}^{2+}$ free PBS. Lymphocytes were isolated from blood using Histopaque 1077 and the cells were suspended in RPMI 1640.

\section{Viability assessment of lymphocytes}

The lymphocytes were checked for their viability before the start and after the end of the reaction using trypan blue exclusion test [22].

\section{Comet assay (single cell gel electrophoresis)}

A comet assay was performed under alkaline conditions essentially according to the procedure of Singh et al. [23] with slight modifications. Fully frosted microscopic slides pre-coated with $1.0 \%$ normal melting agarose were used (dissolved in $\mathrm{Ca}^{2+}$ and $\mathrm{Mg}^{2+}$ free PBS). Around 10000 cells were mixed with $90 \mu \mathrm{l}$ of $1.0 \%$ low melting point agarose to form a cell suspension and pipetted over the first layer and covered immediately by a cover slip. The slides were placed on a flat tray and kept on water ice for $10 \mathrm{~min}$ to solidify the agarose. The cover slips were removed and a third layer of $0.5 \%$ low melting point agarose $(90 \mu \mathrm{l})$ was pipetted. Cover slips were placed over it and it was allowed to solidify on water ice for $5 \mathrm{~min}$. The cover slips were removed and the slides were immersed in cold lysis $\left(4^{\circ} \mathrm{C}\right)$ solution containing $2.5 \mathrm{M} \mathrm{NaCl}$,

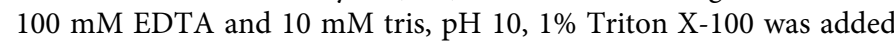
before use for a minimum of $1 \mathrm{~h}$ at $4^{\circ} \mathrm{C}$. After lysis, DNA was allowed to unwind for $30 \mathrm{~min}$ in alkaline electrophoretic solution consisting of $300 \mathrm{mM} \mathrm{NaOH}$ and $1 \mathrm{mM}$ EDTA, $\mathrm{pH}>13$. Electrophoresis was performed at $4^{\circ} \mathrm{C}$ in field strength of $0.7 \mathrm{~V} / \mathrm{cm}$ and $300 \mathrm{~mA}$ current. The slides were then neutralized with cold $0.4 \mathrm{M}$ Tris, $\mathrm{pH}$ 7.5, stained with $80 \mu \mathrm{l}$ ethidium bromide $(20 \mathrm{mg} / \mathrm{ml})$ and covered with a cover slip. They were then placed in a humidified chamber to prevent drying of the gel and analyzed the same day. Slides were scored using an image analysis system (Komet 5.5; Kinetic Imaging, Liverpool, UK) attached to an Olympus (CX41) fluorescent microscope (Olympus Optical Co., Tokyo, Japan) and a COHU 4910-integrated CC camera (equipped with $510-560 \mathrm{~nm}$ excitation and $590 \mathrm{~nm}$ barrier filters) (COHU, San Diego, CA, USA). Images from 50 cells (25 from each replicate slide) were analyzed. The parameter taken to assess lymphocytes DNA damage was tail length (migration of DNA from the nucleus, $\mu$ meter).

\section{Thiobarbituric-acid-reactive substance (TBARS) esti- mation}

Thiobarbituric-acid-reactive substance (TBARS) was determined according to the method of Ramanathan et al. [24]. A cell suspension $\left(1 \times 10^{5} / \mathrm{ml}\right)$ was incubated in the presence of white light as indicated in the legend at $37^{\circ} \mathrm{C}$ in a total volume of $3 \mathrm{ml}$ for $1 \mathrm{~h}$. The reaction was stopped by the addition of $1 \mathrm{ml}$ of $5 \mathrm{~N} \mathrm{NaOH} .1 .5 \mathrm{ml}$ of the reaction mixture was added to $0.5 \mathrm{ml}$ of $10 \%$ TCA and $0.5 \mathrm{ml}$ of $0.6 \mathrm{M} \mathrm{TBA}$ (2-thiobarbituric acid) and the mixture incubated in a boiling water bath for $10 \mathrm{~min}$. The absorbance was read at $532 \mathrm{~nm}$.

\section{Results}

The hydroxyl radical is considered to be the ultimate species responsible for DNA damage. Figure 1 shows 5-FU alone at lower concentration generates a significant amount of hydroxyl radical. Moreover, at high concentration of 5-FU a biphasic pattern was observed. However, when $5-\mathrm{FU}$ is combined with RF the photoexcitation of 5-FU is masked. 


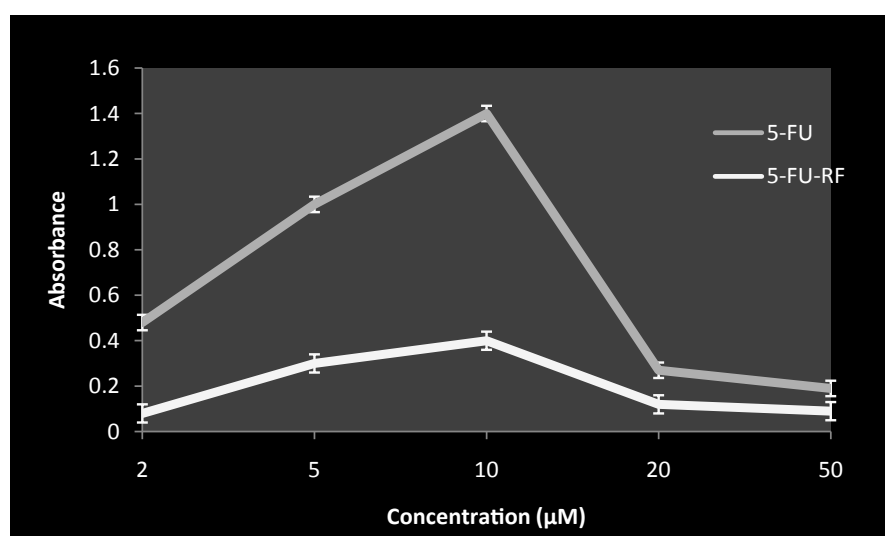

Figure 1. Hdroxyl radical generation by 5-FU both in presence and absence of RF on exposure to white light.

$\mathrm{RF}(50 \mu \mathrm{M})$ with indicated concentration of 5-FU was incubated in white light for $1 \mathrm{hr}$ at room temperature in ratio1:1. Values reported are \pm SEM of three independent experiments. Ratio was maintained same throughout the study design in case of combination.

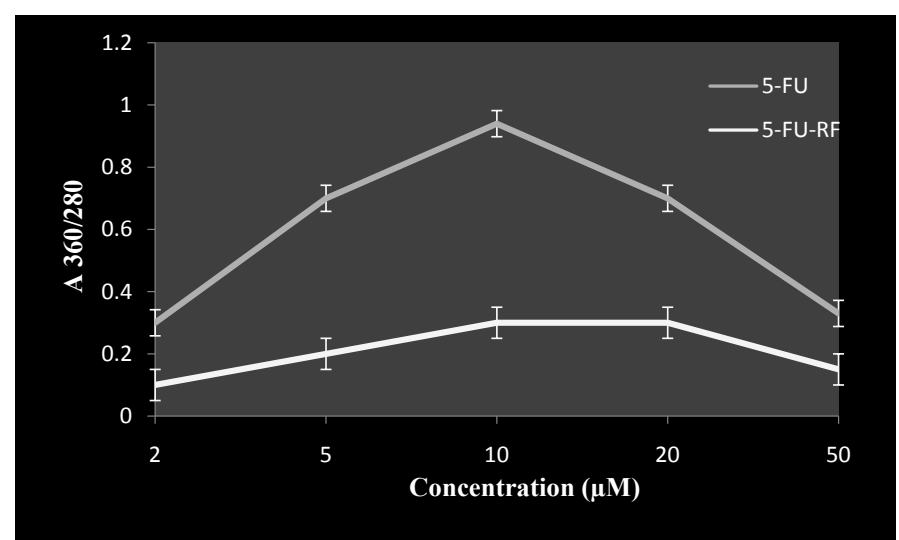

Figure 2. Effect of RF on 5-FU induced carbonyl formation in presence of white light. BSA $(2 \mathrm{mg} / \mathrm{ml})$ with $50 \mu \mathrm{M} \mathrm{RF}$ and indicated concentration of 5 -FU in total volume of $1.0 \mathrm{ml}$, was incubated in presence of white light for $1 \mathrm{hr}$ at room temperature in ratio1:1. Values reported are \pm SEM of three independent experiments. $P$ value is calculated which was $<0.05$.

Carbonyl groups are known as markers of oxidative damage in proteins. Carbonyl estimation was done to evaluate the effect of photoilluminated 5-FU in the presence of RF on BSA as a target protein. Figure 2 shows the rise in the carbonyl groups reached a certain level at $10 \mu \mathrm{M}$, after which no increase in oxidative damage of protein was observed. However, on addition of RF in the reaction the photo excitation of 5-FU was inhibited. These observations demonstrate the possibility of some interaction between RF and 5-FU at lower concentrations which contribute to a decrease in toxicity of 5-FU.

To shed further light on the outcome of 5 -FU on structural modification of BSA in presence of RF, CD spectra was recorded. In Figure 3 the addition of small amount of 5-FU causes the distortion of $\mathrm{CD}$ spectrum which is demonstrated by disordered form of $\alpha$-helix. However, on addition of RF in the reaction the drug caused a restoration of the spectrum.

Gel electrophoresis was performed using pUC18 plasmid DNA with 5-FU in presence or absence of photoilluminated RF. Figure 4 shows that in case of 5 -FU and RF combination, the RF exhibited significant reduction in cleavage activity of 5-FU (lane c). The nicking activity is minimally affected by the incorporation of 5-FU at higher concentration in the reaction medium suggesting that 5-FU behaving in biphasic pattern (lane d-g). Moreover, RF alone does not cause nicking of plasmid at concentration of $50 \mu \mathrm{M}$ (lane h). Thus, plasmid nicking assay suggest that the RF retards the photoexcitation potential of 5-FU.

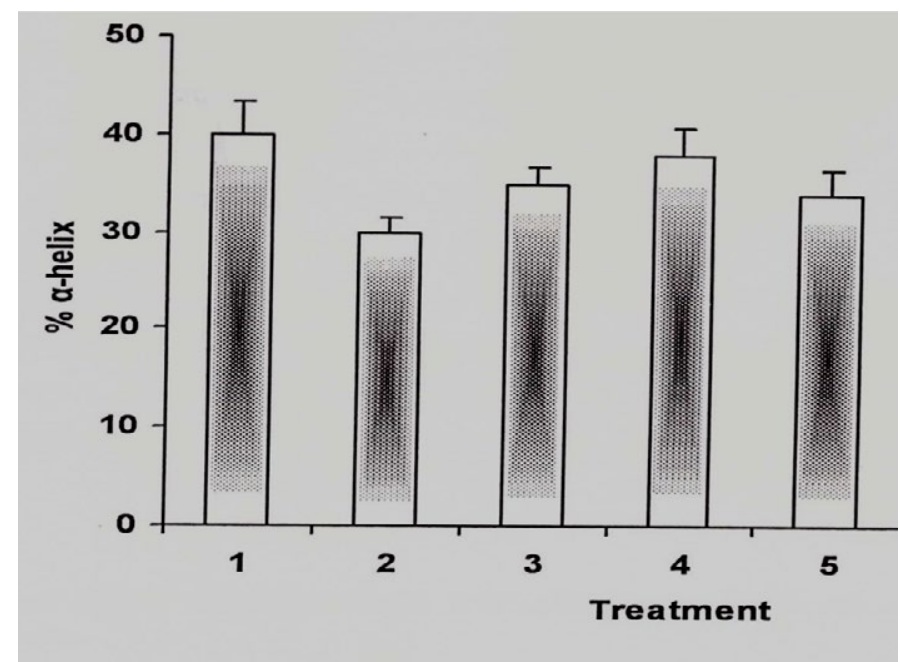

Figure 3. $\alpha$-helical content of BSA under different conditions.

The reaction mixture containing BSA was incubated in white light for $1 \mathrm{hr}$ at room temperature under following conditions and in case of 5-FU-RF combination the ratio was $1: 1$

1: BSA alone $(2 \mu \mathrm{M})$

2: BSA: 5-FU $(2: 10 \mu \mathrm{M})$

3: BSA: RF $(2: 50 \mu \mathrm{M})$

4: BSA: 5-FU-RF $(2: 10: 50 \mu \mathrm{M})$

5: BSA: 5-FU $(2: 20 \mu \mathrm{M})$

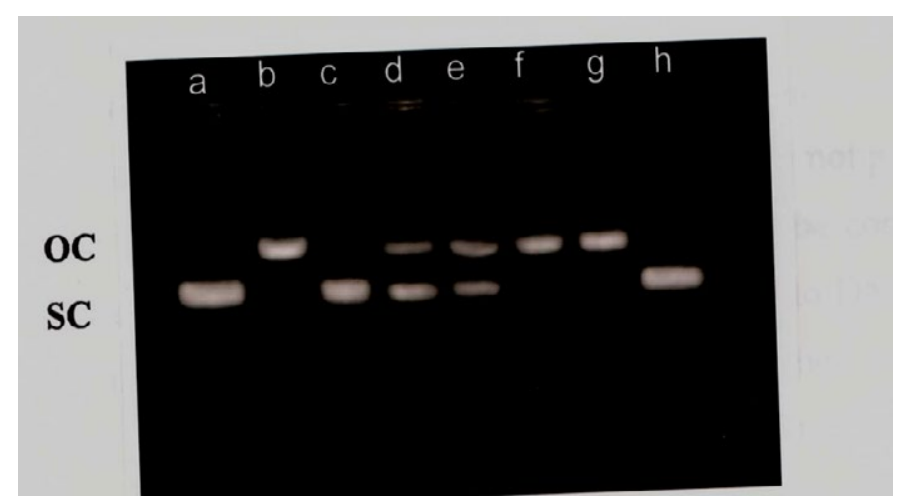

Figure 4. Agarose gel electrophoresis pattern of pUC 18 DNA upon treatment with 5-FU both in presence and absence of RF under white light.

Reaction mixture containng $0.50 \mu \mathrm{g}$ of pUC $18 \mathrm{DNA} 50 \mu \mathrm{M}$ RF and indicated concentration of 5-FU was incubated in presence of white light for $1 \mathrm{hr}$ at room temperature.

Lane a: DNA alone

Lane b: DNA-5-FU $(10 \mu \mathrm{M})$

Lane c: DNA-5-FU-RF (10: $50 \mu \mathrm{M})$

Lane d: DNA-5-FU $(50 \mu \mathrm{M})$

Lane e: DNA-5-FU $(20 \mu \mathrm{M})$

Lane f: DNA-5-FU $(10 \mu \mathrm{M})$

Lane g: DNA-5-FU $(5 \mu \mathrm{M})$

Lane h: DNA-RF $(50 \mu \mathrm{M})$ 
Lymphocytes treated with 5-FU alone (Figure 5) lead to significant oxidative DNA damage as measured by increase in tail length. However, higher concentration apparently had less effect on oxidative DNA damage. This is likely due to the dimerization of drug by inhibitings its own oxidative potential. Moreover, RF and 5-FU combination in Figure 6 shows considerable inhibition in DNA damage as compared to 5 -FU alone. These results suggest an ameliorative role of RF in the genotoxicity of 5-FU.

To establish the production of ROS at cellular levels, the formation of TBARS was analyzed as is shown in figure 7. 5-FU alone at lower concentration lead to considerable formation of TBARS in the presence of white light where as the combination of RF and 5-FU resulted in decreased formation of TBARS as compared to 5-FU alone.

\section{Discussion}

5-FU a pyrimidine analogue is an important anticancer drug used widely in the treatment of a variety of solid tumors such as colorectal, stomach, breast and liver carcinomas [25]. The oncologists are using combination of anticancer drugs with adjuvant for chemotherapy. Thus, interest grew to study the susceptibility of RF which very likely

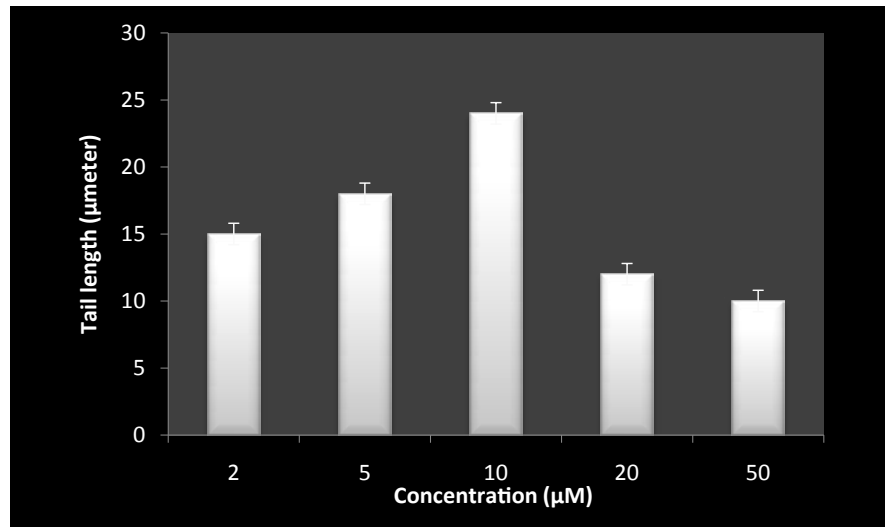

Figure 5. DNA breakage by 5-FU on exposure to white light in human peripheral lymphocyte as measured by comet assay.

Reaction mixture $(1 \mathrm{ml})$ containing $1 \times 10^{5}$ cells, was incubated in presence of white light with indicated concentration of 5-FU for $1 \mathrm{hr}$ at room temperature. Values reported are \pm SEM of three independent experiments. P value is calculated which was $<0.05$.

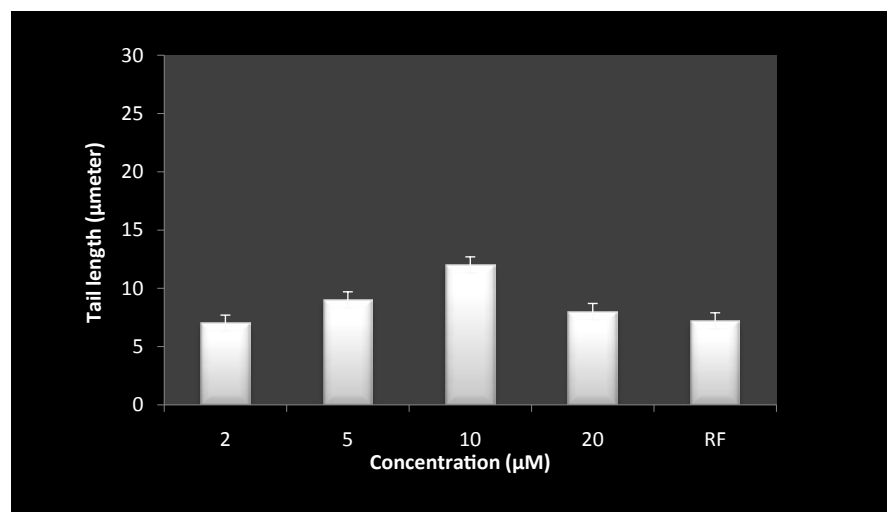

Figure 6. Inhibition of 5-FU induced DNA breakage by RF on exposure to white light in human peripheral lymphocytes as measured by comet assay.

Reaction mixture $(1 \mathrm{ml})$ containing $1 \times 10^{5}$ cells, $50 \mu \mathrm{M} \mathrm{RF}$ and indicated concentration of 5-FU was incubated in presence of white light for $1 \mathrm{hr}$ at room temperature. last bar represent RF alone at the concentration of $50 \mu \mathrm{M}$. Values reported are \pm SEM of three independent experiments. $\mathrm{P}$ value is calculated which was $<0.05$.

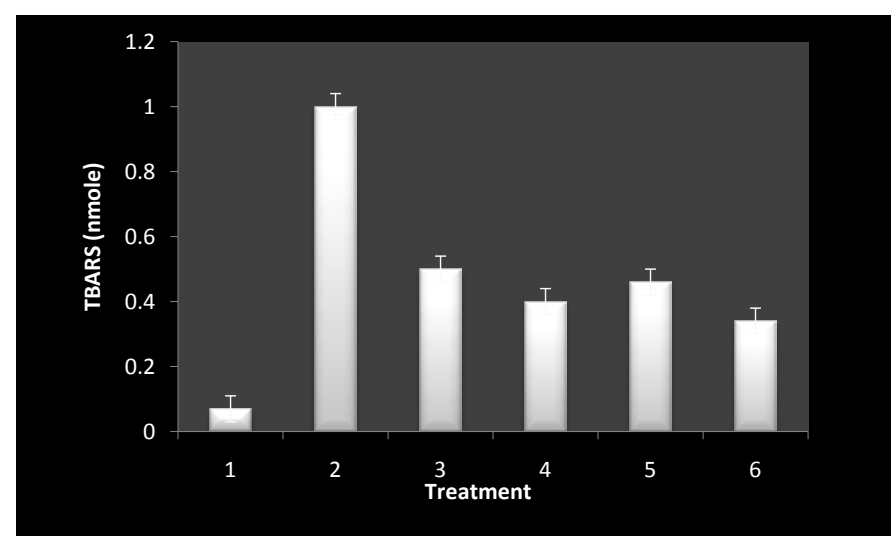

Figure 7. TBARS generation by incubation of lymphocytes under different conditions.

The isolated cells $\left(1 \times 10^{5}\right)$ were incubated under different conditions in presence of white light for $1 \mathrm{hr}$ at room temperature. Values reported are \pm SEM of three independent experiments. $\mathrm{P}$ value is calculated which was $<0.05$.

1: control

2: 5-FU alone $(10 \mu \mathrm{M})$

3: 5-FU-RF (10: $50 \mu \mathrm{M})$

4: $\mathrm{RF}(50 \mu \mathrm{M})$

5: 5 -FU $(20 \mu \mathrm{M})$

6: 5 -FU $(50 \mu \mathrm{M})$

function as adjuvant to induce modification in presence of 5-FU. RF is an easily absorbed, water soluble micronutrient that is obtained from dietary sources. We chose RF as an adjuvant/photo sensitizer because there are no known toxic side effects associated with even large doses of this membrane permeable vitamin [17].

Free radicals have been shown to be capable of damaging many cellular components such as DNA, protein, and lipids [25]. Oxidative modification of proteins in vivo may affect a variety of cellular functions involving, signal transduction mechanisms, transport system and enzymes. In present study, data show that 5-FU was found to behave in a biphasic pattern with lower concentrations exhibiting phototoxic effect while the higher molar ratios diminish this effect. Carbonyl estimation, plasmid nicking assay, comet assay and TBARS estimation results were in accordance. Our study is analogous to microbial study reported by Yamane et al. [26] where the growth of Arthrobacter species was inhibited by 5 -FU and inhibition was reversed by RF. This behaviour continues similar in our study which we can suggest based on the results obtained from carbonyl assay where oxidative damage to albumin protein by 5 -FU at lower concentration was inhibited when RF was added in the reaction mixture. Moreover, the cleavage efficiency of 5-FU on pUC 18 DNA with RF in the reaction medium followed the same outline. The 5-FU underwent masking of photoreaction in presence of RF at specific ratios. It is assumed that the interaction of RF with 5-FU may mask the photoexcitable group in 5-FU, leading to decreased production of ROS and hence result in reduced fragmentation of cellular DNA, as is also depicted by the decrease in the tail length of the comet when lymphocyte was treated with 5-FU at lower concentration in presence of RF. It is noteworthy to mention that RF has been postulated as a viable sensitizer for the in-vivo photoxidative degradation of naturally or externally added substrate [27].

In the context of a photodynamic reaction, the structural 
modification of protein by 5 -FU alone at lower concentration was observed with the help of circular dichroism measurement. This attributed the change in $\alpha$-helical content suggesting distortion in its structure which was restored at higher concentration of 5-FU. The trend was consistence with that obtained by Hu et al. [28]. Apparently, the lower concentration of drug was interactive with the target biomolecules. This validated the observation of lower concentrations interfering with the reaction. However, in order to rule out the reason for amelioration of ROS generation when 5-FU was exposed to white light in presence of RF spectral analysis was conducted. Results of spectrum shows the formation of a complex between the 5-FU and $\mathrm{RF}$ (data not shown) in presence of white light. Therefore, we can suggest that the complex formation between 5-FU and RF may play a role in ruling out toxic effect of 5-FU in presence of RF as the group responsible for the ROS generation i.e carbon 5 of $5-\mathrm{FU}$ is shielded by alloxazine ring of RF. Interactive forces within the drug molecules play a pivotal role at higher molar ratios as a consequence the dimerization probably shielding the group that are involved in generating oxidative stress in presence of white light. Our study is supported by Hatta et al. who suggested the dimerization at higher concentrations as the possible reason for the observed pattern [9].

As most anticancer drugs are transparent to daylight, so the presence of other compounds likes RF which are capable of absorbing environmental light may affect their ability to participate in photosensitization reactions. Thus, our study may help the oncologist to formulate the therapy by using RF as a modulator in 5-FU based chemo-phototherapy. There is certainly potential to further improve chemo-phototherapy combinations as well as to rationally develop new photosensitizing drugs if a better mechanistic understanding of the interaction of these modalities can be gained. Cancer survivors are increasingly turning to complementary and alternative medicine to manage short and long term treatment squealed. Dietary supplements in this regard could belong to the category of multivitamin, minerals and herbs. Health professionals have increasingly acknowledged that dietary supplement drug interaction may adversely interact with prescribed medications for treating cancer [3].

The compilation of our results suggest that the toxicity of the 5-FU can be significantly reduced and blunted using RF as a photosensitizer in chemo-phototherapy. Further studies at the in vivo level however would explain the possibilities of such reactions in living system under a particular treatment therapy.

\section{Acknowledgment}

The authors sincerely acknowledge the financial assistance provided by the University Grant Commission (UGC), New Delhi under SAP program, DST- FIST and the facilities provided by Department of Biochemistry, Aligarh Muslim University. We are also thankful to the fellows who directly or indirectly helped us during different phases of experimentation to produce this work.

\section{References}

1. Longley DB, Harkin DP, Johnston PG (2003) 5-fluorouracil: mechanisms of action and clinical strategies. Nat Rev Cancer 3: 330-338. [Crossref]

2. Finsterer J, Ohnsorge P (2013) Influence of mitochondrion-toxic agents on the cardiovascular system. Regul Toxicol Pharmacol 67: 434-445. [Crossref]

3. Castillo C, Criado S, Díaz M, Norman AG, (2007) Riboflavin as a sensitiser in the photodegradation of tetracyclines. Kinetics, mechanism and microbiological implications. Dyes Pigm 72: 178-184.
4. Fontana M, Blarzino C, Pecci L (2012) Formation of 3-nitrotyrosine by riboflavin photosensitized oxidation of tyrosine in the presence of nitrite. Amino Acids 42: 18571865. [Crossref]

5. Sato K, Sakakibara N, Hasegawa K, Minami H, Tsuji T (2000) A preliminary report of the treatment of blue nevus with dermal injection of riboflavin and exposure to nearultraviolet/visible radiation (ribophototherapy). J Dermatol Sci 23: 22-26. [Crossref]

6. Cui Z, Huang Y, Mo Q, Wang X, Qian K (2008) Inactivation of lymphocytes in blood products using riboflavin photochemical treatment with visible light. Photochem Photobiol 84: 1195-1200. [Crossref]

7. Eubanks LM, Dickerson TJ, Janda KD (2005) Vitamin B2-mediated cellular photoinhibition of botulinum neurotoxin A. FEBS Lett 579: 5361-5364. [Crossref]

8. Yasumoto M, Yamawaki I, Marunaka T, Hashimoto S (1978) Studies on anti-tumor agents Syntheses and anti-tumor activities of 1-(tetrahydro-2-furanyl)-5-fluorouracil and ,3-bis(tetrahydro-2-furanyl)-5-fluorouracil. J Med Chem 2: 738-741. [Crossref]

9. Hatta H, Zhou L, Mori M, Teshima S, Nishimoto S (2001) N(1)-C(5')-linked dimer hydrates of 5 -substituted uracils produced by anodic oxidation in aqueous solution. $J$ Org Chem 66: 2232-2239. [Crossref]

10. Lamberti M, Porto S, Marra M, Zappavigna S, Grimaldi A, et al. (2012) 5-Fluorouracil induces apoptosis in rat cardiocytes through intracellular oxidative stress. $J$ Exp Clin Cancer Res 31: 60. [Crossref]

11. El-Sayyad HI, Ismail MF, Shalaby FM, Abou-El-Magd RF, Gaur RL, et al. (2009) Histopathological effects of cisplatin, doxorubicin and 5-flurouracil (5-FU) on the liver of male albino rats. Int J Biol Sci 5: 466-473. [Crossref]

12. Han R, Yang YM, Dietrich J, Luebke A, Mayer-Pröschel M, et al. (2008) Systemic 5 -fluorouracil treatment causes a syndrome of delayed myelin destruction in the central nervous system. J Biol 7: 12. [Crossref]

13. Zhou C, Zhang M, Huang P, Tu H, Wang Z, et al. (2014) Assessment of 5-fluorouracil and 4-nitroquinoline-1-oxide in vivo genotoxicity with Pig-a mutation and micronucleus endpoints. Environ Mol Mutagen 55: 735-740. [Crossref]

14. Gulten T, Evke E, Ercan I, Evrensel T, Kurt E, et al. (2011) Lack of genotoxicity in medical oncology nurses handling antineoplastic drugs: effect of work environment and protective equipment. Work 39: 485-489. [Crossref]

15. Husain E, Naseem I (2008) Riboflavin-mediated cellular photoinhibition of cisplatininduced oxidative DNA breakage in mice epidermal keratinocytes. Photodermatol Photoimmunol Photomed 24: 301-307. [Crossref]

16. Hassan I, Chibber S, Aijaz AK, Naseem I (2012) Riboflavin Ameliorates Cisplatin Induced Toxicities under Photoillumination. PLoSONE 7: e36273. [Crossref]

17. Hassan I, Chibber S, Naseem I (2010) Ameliorative effect of riboflavin on the cisplatin induced nephrotoxicity and hepatotoxicity under photoillumination. Food Chem Toxicol 48: 2052-2058. [Crossref]

18. Hassan I, Chibber S, Naseem I (2013) Vitamin B2: a promising adjuvant in cisplatin based chemoradiotherapy by cellular redox management. Food Chem Toxicol 59: 715 723. [Crossref]

19. Xiao S, Qiu C, Jin E, Chen Y, Louis P, et al. (2005) Effects of solvent on fabrication of polymeric light emitting devices. Mater Lett 59: 694-696.

20. Gutteridge JM (1984) Reactivity of hydroxyl and hydroxyl-like radicals discriminated by release of thiobarbituric acid-reactive material from deoxy sugars, nucleosides and benzoate. Biochem J 224: 761-767. [Crossref]

21. Nakagawa K, Kaku M, Abukawa T, Aratani K, Yamaguchi M, et al. (2007) Copper (II) ions convert catechins from antioxidant to prooxidant in protein carbonyl assay formation. J Health Sci 53: 591-595. [Crossref]

22. Chen YH, Yang JT, Martinez HM (1972) Determination of the secondary structures of proteins by circular dichroism and optical rotatory dispersion. Biochemistry 11: 41204131. [Crossref]

23. Pool-Zobel BL, Guigas C, Klein R, Neudecker C, Renner HW, et al. (1993) Assessment of genotoxic effects of lindane. Food Chem Toxicol 3: 184-191. [Crossref]

24. Ito T, Tanabe K, Yamada H, Hatta H, Nishimoto S (2008) Radiation- and photo-induced activation of 5-fluorouracil prodrugs as a strategy for the selective treatment of solid tumors. Molecules 13: 2370-2384. [Crossref]

25. Chibber S, Farhan M, Hassan I, Naseem I (2012) Novel aspect of chemophototherapy in treatment of cancer. Tumour Biol 33: 701-706. [Crossref]

26. Ramanathan R, Das NP, Tan CH (1994) Effect of g-Linolenic acid, flavonoids and vitamins on cytotoxicity and lipid peroxidation. Free Radic Biol Med 16: 43-48. [Crossref] 
27. Heelis PF (1982) The photophysical and photochemical properties of flavins (isoalloxazines). Chem Soc Rev 1: 15-39.
28. Hu YJ, Liu Y, Shen XS, Fang XY, Qu SS (2005) Study on the interaction between 1-hexylcarbamoyl-5-fluorouracil and bovine serum albumin. J Mol Struct 738: $143-147$.

Copyright: (C2015 Husain E. This is an open-access article distributed under the terms of the Creative Commons Attribution License, which permits unrestricted use, distribution, and reproduction in any medium, provided the original author and source are credited. 